\title{
TEM Study of Supercritical Water Corrosion in 310S and 800H Alloys
}

\author{
Babak Shalchi Amirkhiz, Jian Li, Yimin Zeng and Wenyue Zheng \\ CanmetMATERIALS, Natural Resources Canada, Hamilton, Canada
}

Corrosion resistance is one of the key factors in materials selection for Gen IV supercritical water-cooled reactor (SCWR) concept; especially when it comes to selection for fuel cladding. Amongst the candidate materials, $310 \mathrm{~S}$ austenitic stainless steel and INCOLOY ${ }^{\circledR} 800 \mathrm{H}$ are deemed very promising. A summary of the previous corrosion studies on candidate alloys can be found elsewhere $[1,2]$. In this work TEM study of FIB sectioned test coupons is presented in our effort to understand the microstructural evolution of these alloys upon SCW exposure. Characterization of the sigma phase as a high temperature $\mathrm{Cr}-\mathrm{Fe}$ intermetallic that is brittle in nature and potentially detrimental to the mechanical properties [3] is discussed.

Coupons $(20 \times 10 \times 2 \mathrm{~mm})$ were cut from commercial austenitic steel $310 \mathrm{~S}$ and $800 \mathrm{H}$ plates. The coupons were placed in a static autoclave containing deionized water and exposed to $\mathrm{SCW}$ condition $\left(625^{\circ} \mathrm{C}\right.$, $25 \mathrm{MPa}$ ) for 250 hours. Cross sectional transmission electron microscopy (TEM) samples were prepared using the FEI Helios NanoLab ${ }^{\mathrm{TM}}$ DualBeam ${ }^{\mathrm{TM}}$ FIB microscope from the top surface of the coupons [4]. A protective layer of $\mathrm{Pt}$ was first deposited on the surface to protect the corrosion layer. TEM samples were observed using the FEI Tecnai Osiris ${ }^{\mathrm{TM}}$ TEM equipped with Super X field emission gun (FIG) and ChemiSTEM $^{\text {TM }}$ X-ray detection technology operating at $200 \mathrm{kV}$. EDX analyses were done in STEM High angle annular dark field (HAADF) imaging mode. The Esprit software was used for qualitative and quantitative elemental mapping. Conventional bright field/ dark field imaging and electron diffraction techniques were used to characterize different corrosion regions and for phase identification.

Fig 1 shows EDX elemental maps from the top region of a TEM specimen prepared from the 310S coupon. The top layer contains very fine grains of $\mathrm{CrO} 2$ with average grain size of $\sim 50 \mathrm{~nm}$. A layer featuring recrystallized $\gamma$ grains below the oxide layer is highlighted in Figure 2 and is also visible in the $800 \mathrm{H}$ sample in Fig 3. The average thickness of top chromium oxide layer for $310 \mathrm{~S}$ and $800 \mathrm{H}$ samples were $270 \mathrm{~nm}$ and $240 \mathrm{~nm}$ respectively; and the thickness of the sublayer Cr-depleted recrystallized $\gamma$ regions were $760 \mathrm{~nm}$ and $800 \mathrm{~nm}$ respectively. A selected area diffraction pattern (SAD) taken from this region showed superlattice spots coming from a $\sigma$ grain grown coherently on the $\gamma$ (Fig 2). An orientation relationship between the $\gamma$ and $\sigma$ was evident in both alloys. EDX mapping along with SAD analysis revealed that in the base metal in vicinity of the recrystallized region, the $\gamma$ grains contained a network of very fine coherent $\sigma$ nuclei. An example is shown in Fig 4 where an SAD from a large $\gamma$ grains (region 1) below the recrystallized region 2 shows superlattice spots from the $\sigma$. The dark field image in Figure 4 acquired from, $\left(\begin{array}{lll}0 & 0 & 2\end{array}\right)$ reflection of $\sigma$ reveals a network of $\sigma$ within the $\gamma$ matrix in the $800 \mathrm{H}$. Similar phenomenon was observed in $310 \mathrm{~S}$. In summary, FIB/TEM provided a method for studying the microstructural changes after SCW exposure. This study sheds light on the nucleation and the evolution of $\sigma$ phase during SCW exposure that may play an important role in corrosion resistance of SCWR candidate alloys.

\section{References}

[1] TR Allen et al, in "Comprehensive Nuclear Materials" ed. TR Allen, (Elsevier) p.279.

[2] Y Tsuchiya et al CORROSION 2007, p. 07415.

[3] CC Hsieh and W Wu, International Scholarly Research Network, vol.2012, ID 732471

[4] J Li, JOM vol. 58 (2006) p.27. 
[5] The authors acknowledge financial support from NRCan program on Energy R\&D (PERD)

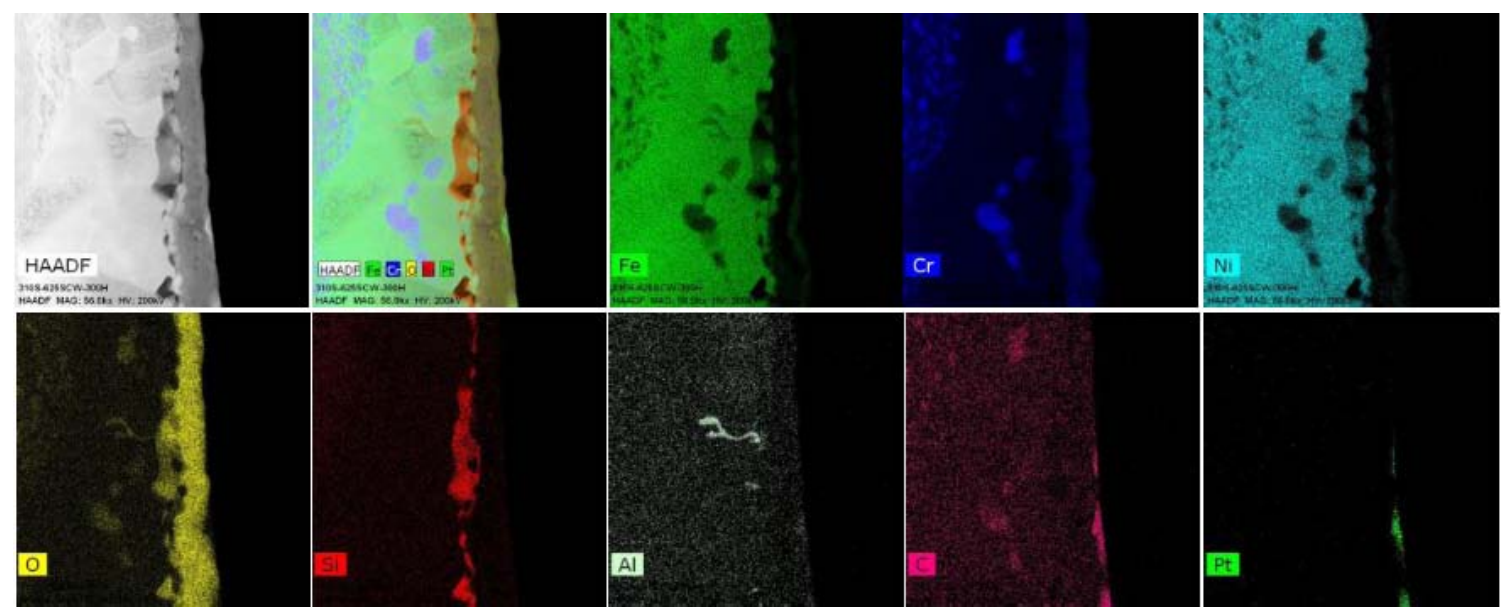

Figure 1. EDX quantified elemental maps of the corroded top surface of the alloy $310 \mathrm{~S}$

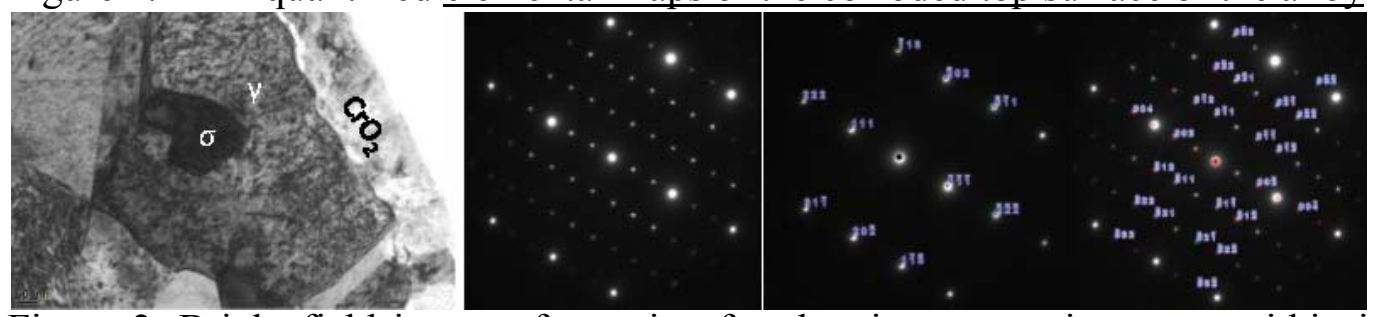

Figure 2. Bright field image of a grain of $\gamma$ showing a $\sigma$ grain grown within it; along with the SAD diffraction patterns taken along [ $\left[\begin{array}{lll}-1 & -2 & 1\end{array}\right] \gamma$ and along $\left[\begin{array}{lll}1 & -3 & 0\end{array}\right] \sigma$ in $310 \mathrm{~S}$.
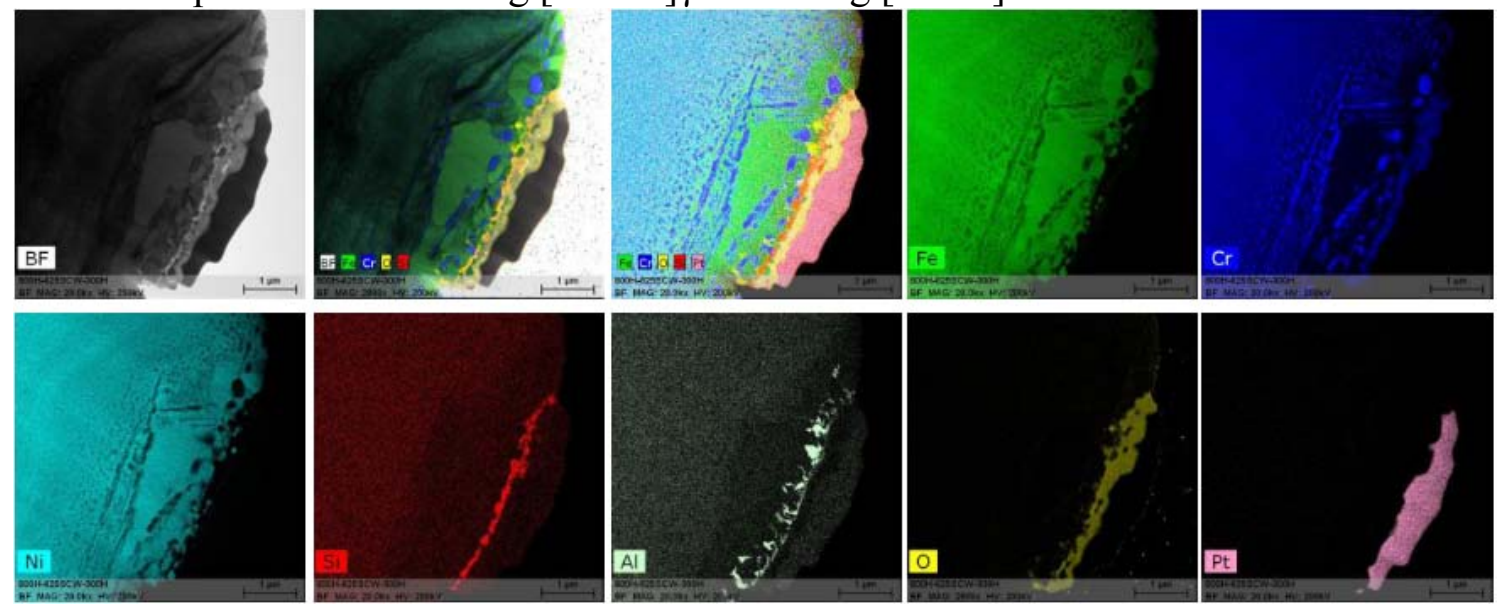

Figure 3. EDX quantified elemental maps of the corroded top surface of the alloy $800 \mathrm{H}$

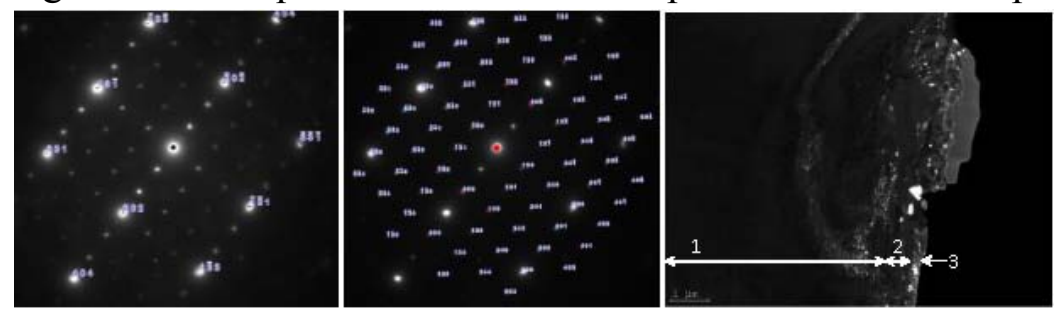

Figure 4. SAD from a $\gamma$ grain in $800 \mathrm{H}$ showing spots from [-3 23 3] zone axis of $\gamma$ (brighter spots) and [2 -10 ] zone axis of $\sigma$. The dark field image is taken using the $\left(\begin{array}{lll}0 & 0 & 2\end{array}\right) \sigma$ reflection. 